\title{
Ez 3,16-21: Ezequiel como sentinela e suas implicações sociorreligiosas
}

\section{Ez 3: 16-21: Ezekiel as sentinel and its socio-religious implications}

\section{Ez 3: 16-21: Ezequiel como centinela y sus implicaciones socio-religiosas}

\author{
Leonardo Agostini Fernandes \\ Submetido em: 18-5-2021 \\ Aceito em: 10-8-2021 \\ * Pontifícia Universidade Católica do Rio de Janeiro \\ Doutor em Teologia Bíblica \\ E-mail: laf2007@puc-rio.br
}

\section{Ez 3: 16-21: Ezequiel como centinela y sus implicaciones socio-religiosas}

\author{
Leonardo Agostini Fernandes
}

\begin{abstract}
RESUMO
O artigo propõe uma análise exegético-teológica do Livro de Ezequiel 3,16-21. Por ser considerado uma inserção redacional, esse texto recebeu e ainda recebe pouca atenção. Artigos e trabalhos monográficos são escassos e nos comentários pouco se encontra. O principal motivo deve-se a Ez 33,1-9, seu paralelo, fazendo com que Ez 3,1621 seja visto como um resumo proléptico. Além disso, existem conexões temáticas com Ez 18,1-32. A presente reflexão, nesse sentido, além de tentar preencher certa ausência, lança um olhar para a figura do profeta Ezequiel com o intuito de compreender o sentido e o alcance da vocação e missão recebidas de YHWH. Sete partes compõem este estudo: Introdução; Tradução segmentada; Notas de crítica textual; Delimitação e organização; Estrutura e gênero literário; Breve comentário exegético-teológico; Considerações finais. A abordagem metodológica empregada ao objeto material contemplou aspectos diacrônicos e sincrônicos.
\end{abstract}

Palavras-chave: Hermenêutica bíblica; profecia; sentinela; teologia da retribuição.

\begin{abstract}
The article proposes an exegetical-theological analysis of Book of Ezekiel 3:16-21. As it is considered an editorial insert, this text has received and continues to receive a limited attention. The articles and monographic works are scarce and almost nothing is found in the comments. The main reason is due to Ez 33:1-9, its parallel, which makes Ez 3:16-21 seen as a prolepsis summary. In addition, there are thematic connections with Ez 18: 1-32. This reflection, in this sense, in addition to trying to fill a certain absence, looks at the figure of the prophet Ezekiel to understand the meaning and scope of the vocation and mission received from YHWH. Seven parts make up this study: Introduction; Segmented translation; Notes of textual criticism; Delimitation and organization; Structure and literary genre; Brief exegetical-theological commentary; Final considerations. The methodological approach to the material object considered diachronic and synchronic aspects.
\end{abstract}

Keywords: Biblical hermeneutics; prophecy; sentinel; theology of retribution.

\section{RESUMEN}

El artículo propone un análisis exegético-teológico de el Libro de Ezequiel 3:16-21. Debido a que se considera una inserción de redacción, este texto ha recibido y sigue recibiendo exigua atención. Los artículos y trabajos monográficos son escasos y en los comentarios casi nada se encuentra. La razón principal se debe a Ez 33:1-9, su paralelo, lo que hace que Ez 3:16-21 sea visto como un resumen proleptico. Además, hay conexiones temáticas con Ez 18: 1-32. Esta reflexión, en este sentido, además de intentar llenar una cierta ausencia, echa una mirada a la figura del profeta Ezequiel para comprender el significado y alcance de la vocación y misión recibida de YHWH. Siete partes componen este estudio: Introducción; Traducción segmentada; Notas de crítica textual; Delimitación y organización; Estructura y género literario; Breve comentario exegético-teológico; Consideraciones finales. El abordaje metodológico del objeto material contempló aspectos diacrónicos y sincrónicos.

Palabras clave: Hermenéutica bíblica; profecía; centinela; teología de la retribución. 


\section{Introdução}

Por meio de várias ações simbólicas, Ez 3,16-21 entrelaça o chamado e a missão do profeta com o tema do pecado, da salvação e da responsabilidade individual. Tudo tem a ver com um amplo contexto sociorreligioso que diz respeito à primeira deportação, ocorrida em 598/97 a.C, à destruição de Jerusalém e à nova deportação em 587/86 a.C. Sinais de um regime monárquico falido. Talvez por causa desses elementos, Ez 3,16-21 passou a ser visto como um dos textos mais difíceis do livro do profeta Ezequiel (EICHRODT, 2001, p. 98-99). ${ }^{1}$

Sob essas perspectivas, pode-se dizer que, interpretando o desterro babilônico, Ezequiel se tornou o primeiro profeta a atribuir um devido peso à responsabilidade pessoal. ${ }^{2}$ Tem-se, igualmente, um olhar para a monarquia infiel e injusta. Então, Ezequiel, um desterrado com seu rei $^{3}$ e sua corte, quis despertar nos exilados uma clara consciência do impacto que os pecados, régio e individual, acarretaram para a inteira sociedade.

Subjaz ao contexto o vivo interesse não apenas pela liderança ou pelo povo, mas por cada indivíduo, chamado a compreender o que significa ser livre e responsável pelos próprios atos e a perceber o alcance social das suas ações ou omissões. Antes de se tornar arauto dessa verdade, Ezequiel experimentou, em primeira pessoa, a força de tal responsabilidade, não só como membro do povo, mas como característica singular da sua vocação e missão proféticas.

Diante do paralelo ad intra, enquanto Ez 3,16-21 tem a ver diretamente com a pessoa do profeta, envolvida com duas categorias, o malvado e o justo, Ez 33,1-9 tem a ver com o povo, destinatário da sentença. Um elemento chave permanece: independente do que acontecer com o malvado, o justo ou o povo, a morte ou a vida de Ezequiel dependerá do cumprimento, ou não, da sua missão (OLLEY, 2009, p. 253). ${ }^{4}$ Isto confirma o fato de que Ezequiel, pela ação ou pela omissão, se tornou responsável, como profeta-sentinela, do vivo interesse de YHWH em relação ao seu povo exilado, bem como para com os remanescentes em Judá-Jerusalém: quer a vida e não a morte do seu povo infiel (Ez 18,1-32; 33,10-20).

\section{Tradução segmentada}

\begin{tabular}{|c|c|c|}
\hline E aconteceu ao final de sete dias. & $16 \mathrm{a}$ & 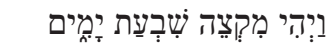 \\
\hline Veio a Palavra de YHWH a mim, dizendo: & $16 \mathrm{~b}$ & 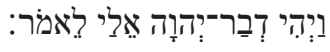 \\
\hline "Filho do homem, te ponho como sentinela & $17 \mathrm{a}$ & רֶּן־אָדָם צָפָּה נְתַתִּיך \\
\hline para a casa de Israel; & & 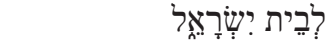 \\
\hline ouvirás de minha boca uma palavra & $17 b$ & 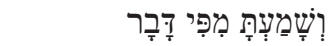 \\
\hline e os alertarás da minha parte. & $17 \mathrm{c}$ & 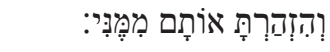 \\
\hline Quando eu disser ao malvado: & $18 \mathrm{a}$ & 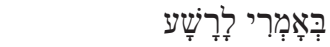 \\
\hline
\end{tabular}

\footnotetext{
${ }^{1}$ Sobre as razões e os motivos que levam a questionar o contexto literário de Ez 3,16-20 (BLOCK, 1997, p. 140).

2 "Ezequiel apareceu no ano 593 a.C., na Babilônia, entre os exilados do primeiro grupo, deportados em 597. Seus escritos nos dão a precisa indicação de como a proclamação do julgamento de Deus sobre Jerusalém se transformou na esperança de salvação, uma vez que a cidade fora destruída" (WOLFF, 2003, p. 115-16).

${ }^{3}$ É significativo que o substantivo "rei" (角), presente trinta e oito vezes no livro, diga respeito, diretamente, apenas três vezes à monarquia de Israel $(E z$ 1,2; 7,27; 17,16). Chama a atenção, igualmente, que em Ez 20,33, com fortes ecos da libertação do Egito, declare que YHWH mesmo reinará. E, no contexto da futura restauração do povo eleito, YHWH anunciou que Judá e Israel seriam novamente reunidos em um único reino (Ez 37,22) e "meu servo Davi” será rei sobre eles (Ez 37,24), e Jerusalém estará livre dos erros de seus monarcas (Ez 43,7.9).

4 "A missão profética tem como objetivo a palavra e ela depende da ordem divina, não da aceitação humana; carrega em si própria uma força tal que, ainda que rejeitada, impõe-se: os exilados, até à força, haverão de reconhecer que Deus thes envia um profeta. Envio de dois gumes: para que se salvem, caso o aceitem, para que não tenham desculpa, caso o rejeitem" (ALONSO SCHÖKEL; SICRE DIAZ, 1991, p. 709).
} 
'Certamente morrerás',

$18 \mathrm{~b}$

e não o alertares

e não falares para alertar um malvado,

quanto ao seu caminho de maldade,

para ele viver;

aquele malvado, por sua culpa morrerá,

mas seu sangue de tua mão reclamarei.

Tu, porém, se alertares um malvado

e não se converte da sua maldade

e do seu caminho de maldade,

ele, por sua culpa, morrerá;

tu, porém, tua alma terás preservado.

Mas se o justo se converte de sua justiça

e comete uma iniquidade

pois ponho um tropeço diante dele,

ele morrerá,

porque não o alertaste,

com seu pecado morrerá

e não serão lembradas as suas justiças

que praticou.

Seu sangue, porém, da tua mão reclamarei.

Mas se tu o alertaste [a ser] justo

para não pecar [e ser] justo

e ele não pecou,

certamente viverá,

pois se deixou alertar,

tu, então, tua alma terás preservado.
$18 \mathrm{c}$

$18 \mathrm{~d}$

$18 \mathrm{e}$

$18 \mathrm{f}$

$18 \mathrm{~g}$

$18 \mathrm{~h}$

$19 \mathrm{a}$

$19 b$

$19 \mathrm{c}$

$19 d$

$20 \mathrm{a}$

$20 \mathrm{~b}$

$20 \mathrm{c}$

$20 \mathrm{~d}$

$20 \mathrm{e}$

$20 \mathrm{f}$

$20 \mathrm{~g}$

$20 \mathrm{~h}$

$20 \mathrm{i}$

$21 \mathrm{a}$

$21 \mathrm{~b}$

$21 \mathrm{c}$

$21 d$

$21 \mathrm{e}$

$21 \mathrm{f}$
מוֹת דָּמוּת

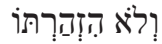

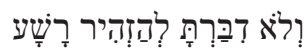

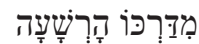

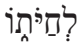

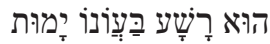

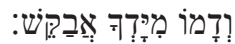

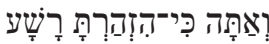

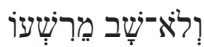

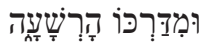

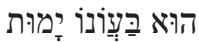

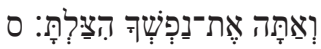

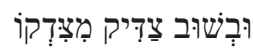

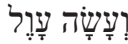

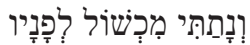

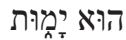

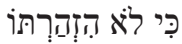

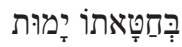

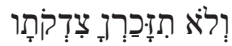

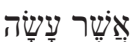

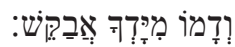

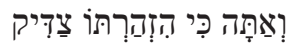

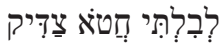

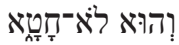

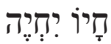

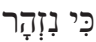

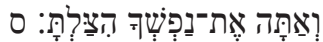

\section{Notas de crítica textual ${ }^{5}$}

v. 18

No v. 18b, a LXX não usou a voz ativa, mas o indicativo futuro na voz passiva: "serás

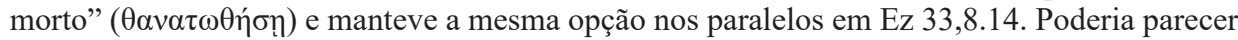
uma mudança insignificante; trata-se, porém, de uma interpretação, indicando que se a morte sobrevier ao ímpio será um efeito das suas ações e não porque YHWH desejou eliminá-lo, pois isso contradiria o que está declarado em Ez 18,23.33; 33,11.

\footnotetext{
${ }^{5}$ Septuaginta (LXX); Texto Massorético Leningradense (TM ${ }^{\mathrm{L}}$ ); Vulgata (Vg); Aparato crítico da Bíblia Hebraica Stuttgartensia (BHS ${ }^{\text {App }}$ ). As diferenças existentes entre Ez 3,16-20 e 33,7-20 podem resultar de uma Vorlage do hebraico ou de um tradutor diferente (OLLEY, 2009, p. 254).
} 
Ainda que a interpretação seja oportuna, a opção da LXX não precisa ser adotada, pois a formulação hebraica, presente em Ez 3,18 (infinito absoluto seguido do mesmo verbo no yiqtol), também foi devidamente mantida em Ez 33,8.14 e encontra-se igualmente atestada em outras dez ocorrências. ${ }^{6}$ Nestas, inclusive, a LXX não apresenta a mesma formulação, mas optou por outro verbo no indicativo futuro médio ( $\dot{\alpha} \pi \mathrm{o} \theta \alpha v \tilde{\eta})$.

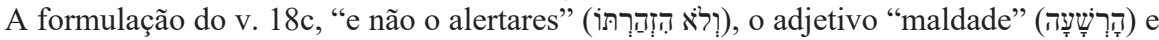
a locução "para ele viver" (לִ לִ ), do v. 18e, estão ausentes em Ez 33,8. Afirmar que o primeiro e o terceiro casos são uma adição seria mera conjectura. E, no segundo caso, ainda que o $\mathrm{TM}^{\mathrm{L}}$ seja maior que a LXX e a Peshitta, está devidamente apoiado pela Vulgata (a via sua impia). A regra - a lição menor deve prevalecer sobre a maior - faria sentido se Ez 33,8 fosse ocupasse uma posição anterior a Ez 3,18.

\section{v. 19}

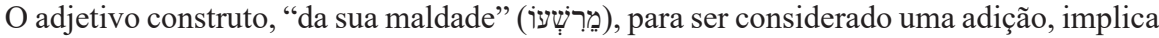
na eliminação do waw da palavra seguinte, obtendo-se uma nova formulação, "e não se converte

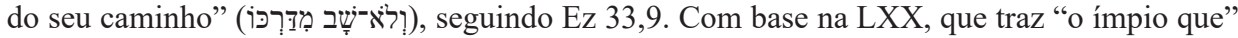

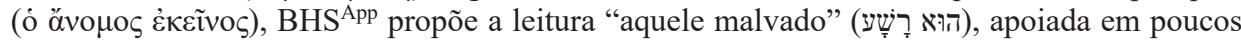
manuscritos hebraicos e conforme o v. 18f. Tal mudança, porém, implica na eliminação do

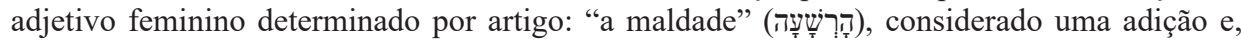
mais uma vez, com base em Ez 33,9.

v. 20

A proposta do BHS App no v. 20a, baseada em Ez 18,24.26; 33,18, de se ler um feminino

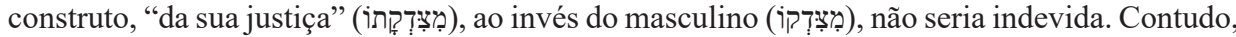
o uso do masculino, ainda que seja um hápax, não deturpa o sentido e nada impede que esteja

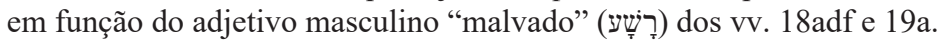

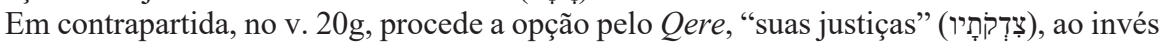

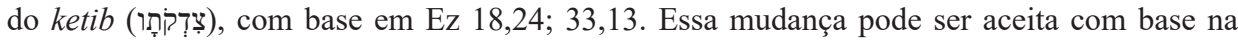
vocalização massorética que indica o plural.

v. 21

Não faz sentido eliminar o sufixo pronominal de terceira pessoa do masculino singular

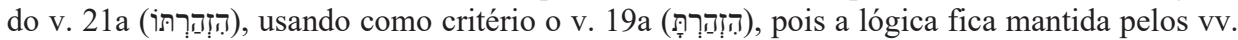

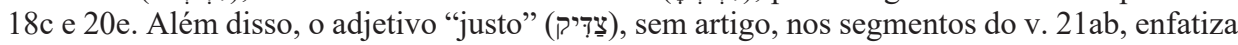
o que deve ser evitado e sua finalidade. Com base na $\mathrm{Vg}$, que manteve os adjetivos, segundo a ordem do $\mathrm{TM}^{\mathrm{L}}$ (si autem tu adnuntiaveris iusto ut non peccet iustus), não é preciso deslocar o

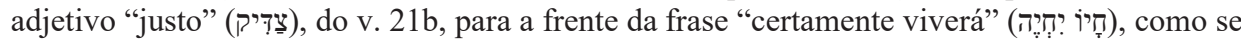

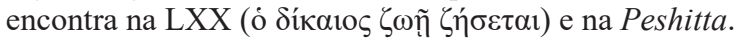

\section{Delimitação e organização ${ }^{7}$}

Ez 3,16-21 está precedido por duas visões, ou êxtases, que teve o profeta Ezequiel. A primeira diz respeito a uma espécie de carro misterioso (Ez 1,4-28), pelo qual se indica a total

\footnotetext{
${ }^{6}$ Gn 2,17; 20,7; 1 Sm 14,44; 22,16; 1Rs 2,37.42; 2Rs 1,4.6.16; Jr 26,8.

${ }^{7}$ Admite-se que Ez 1-7 contenha as primeiras mensagens do profeta que podem ser datadas a partir do quinto ano do exílio em Babilônia (592 a.C.). Essas mensagens preparam a chegada do julgamento divino que trará a destruição de Judá-Jerusalém em 587/86 se não houver conversão (DORSEY, 1999, p. 254).
} 
mobilidade e a liberdade de YHWH em relação ao tempo e ao espaço, em particular ao templo de Jerusalém. A segunda visão diz respeito a um livro escrito nos dois lados com um conteúdo bem específico: "lamentações, prantos e ais" (Ez 2,1-3,11). Esse livro é um símbolo e tem a ver com a vocação e missão do profeta. ${ }^{8}$

Um dado curioso pode ser evidenciado: A primeira visão parece que foi interrompida pela segunda que prossegue em Ez 3,12-15. Nessa continuação, não só a glória de YHWH deixou o templo de Jerusalém, mas até o profeta foi arrebatado para um local específico na Babilônia: "Tel Abib... junto ao rio Cobar" (v. 15).

No tocante ao texto posterior, Ez 3,22-27 tem a ver com o que ocorreu antes do cerco de Jerusalém e retrata uma experiência de limitação, isto é, o profeta, ao contrário de YHWH, perde a liberdade, a mobilidade e o direito de falar. Isso, de certa forma, parece contradizer a constituição de Ezequiel como sentinela, pois o profeta foi encerrado dentro de casa e ficou privado da palavra. Além disso, sobre o profeta não vem a Palavra de YHWH, mas atua a mão de YHWH (Ez 3,22), que, junto ao espírito de YHWH, coloca o profeta em movimento.

Nota-se que Ez 3,16-21 quebra, ou faz uma pausa, na sequência narrativa, pois a partícula adverbial de lugar, "ali" (שָָם), no início de Ez 3,22, liga-se perfeitamente com a referência ao

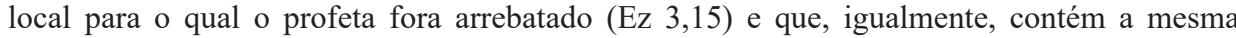
partícula. Certa continuidade poderia estar assegurada pela referência temporal citada pois Ezequiel, falando em primeira pessoa, disse que permaneceu "ali", junto aos exilados, por sete dias $($ Ez 3,15) e que, após sete dias (repetiu-se a referência numérica), a palavra de YHWH lhe foi dirigida $(E z 3,16)$. Tal continuidade, porém, é perturbada pela sequência: "permaneci ali"

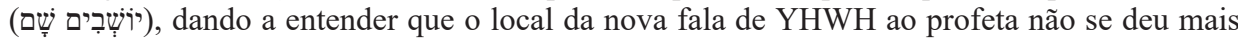
junto ao rio Cobar, mas em Jerusalém.

Nesse sentido, Ez 3,16-21 poderia estar em relação à segunda visão (Ez 2,1-3,11) e os dois textos, juntos, permitiram apresentar, devidamente, a identidade e a missão de Ezequiel. Foi constituído profeta, pelo livro que recebeu, comeu e que parecia doce na boca (Ez 3,1-3), indicador da Palavra de YHWH, que lhe atribuiu uma missão específica: ser sentinela diante do povo para lhe falar tudo o que ouvir de YHWH (Ez 3,4.17).

Do ponto de vista formal, Ez 3,16-21 está bem elaborado e sem rupturas. Tudo gira em torno da imagem da sentinela (צפֶָ), atribuída a Ezequiel (v. 17a). Se, por um lado, o profeta foi feito o interlocutor de YHWH; por outro lado, foi feito mensageiro para interagir com o povo. Há um dado singular na fala de YHWH: o entrelaçamento entre o que o profeta vê como sentinela, ouve e deve falar ao povo. Nesse sentido, visão, audição e fala são os pontos constitutivos do chamado e da missão de Ezequiel.

A lógica interna de Ez 3,16-21 é mantida por diversos elementos.

Em primeiro lugar, estão os elementos relacionados com a comunicação: Quem fala: YHWH (v. 16b); Com quem se fala: Ezequiel, denominado de "filho do homem"; Para quem se fala: "casa de Israel" (v. 17a); O que se fala: "ouvirás de minha boca uma palavra" (v. 17b); Por que se fala: "os alertarás da minha parte" (v. 17c).

Em segundo lugar, está o desdobramento da comunicação, segundo a doutrina da

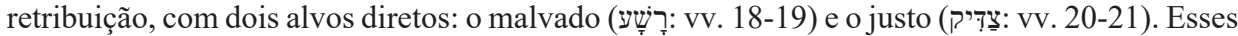
alvos, além de ser os dois polos de uma ação judicial, pela qual se determina quem é culpado e quem é inocente, são os destinatários da palavra de YHWH confiada ao profeta que, também, poderá sofrer sérias consequências por sua obediência ou desobediência à Palavra, isto é, se cumpriu ou não o seu papel como sentinela a favor dos implicados na sua missão.

\footnotetext{
${ }^{8} \mathrm{O}$ livro do profeta Ezequiel possui muitos textos que podem ser classificados como apocalípticos, em particular as visões que atestam uma teofania com traços cosmológicos. A visão é usada nas revelações de cunho apocalíptico e segue uma espécie de padrão: descrição das circunstâncias, ou ocasião da revelação, a visão em si, a reação do vidente e a explicação que, em geral, é dada através de um anjo (CAHINGA, 2003, p. 40-41).
} 
Ao malvado, destina-se um forte vaticínio: “certamente morrerás" (v. 18b). O adjetivo masculino singular absoluto, רָרָ ocorre quatro vezes (v. 18adg.19a) e uma vez o adjetivo feminino singular absoluto, רִ רָשָָָׁ (v. 19b), qualificando a ação. Esse malvado continua presente na fala de YHWH, quer através do pronome pessoal de terceira pessoa do singular no masculino, "ele" - הוּא (v. 19b), quer pelo sufixo pronominal de terceira pessoa do masculino singular ( ), que ocorre oito vezes (v. 18cefgh. $19 \mathrm{~b}^{2} \mathrm{c}$ ).

Ao justo, também é destinado um vaticínio, “certamente viverá” (v. 21d), mas está na dependência de não ter cometido pecado (v. 21c). O adjetivo masculino singular absoluto, צִִּ ocorre três vezes (v. 20a.21ab). Ao lado disso, ocorre uma vez o substantivo masculino צֶ צִ (v. 20a), e uma vez o substantivo feminino צִ צִדקה (v. 20), ambos no estado construto. O justo também continua presente na fala de YHWH, quer através do sufixo pronominal de terceira pessoa do masculino singular ( ), que ocorre sete vezes, quer pelo pronome pessoal de terceira singular no masculino, הוּא (v. 20d.21c), quer pela primeira pessoa.

Em terceiro lugar, o profeta, denominado de "filho do homem" (v. 17a), é quem, além de ser o interlocutor de YHWH, "a mim" - ארלי (v. 16b), é o personagem confrontado com a palavra a ser dirigida para o malvado (vv. 18-19) e para o justo (vv. 20-21). ${ }^{9}$ De modo singular, a pessoa do profeta assegura a unidade textual, pois está presente quer nos verbos, flexionados na segunda pessoa do masculino singular (vv. 17bc.18cd.19a.20e.21af), quer nos sufixos pronominais de segunda do masculino singular (vv. 18h.19d.20i.21f), bem como em duas ocorrências do pronome pessoal de segunda pessoa do singular do masculino, "tu" - אֵָָּה (v. 19d.21f).

Pela lógica interna, resulta claro que o profeta, por sua identidade e missão, terá a sua vida poupada se cumprir, devidamente, as ordens recebidas de YHWH: "tu, porém, tua alma terás preservado" (v. 19d.21f). Feito sentinela do povo, Ezequiel passa a ser responsabilizado pela morte ou pela vida tanto do malvado como do justo, com uma sentença: "seu sangue, porém, de tua mão reclamarei” (v. 18h.20i). Em ambos os casos, as construções frasais são idênticas e lembram a fala de YHWH a Caim $(\mathrm{Gn} 4,10){ }^{10}$

Se cada um morrerá ou viverá como consequências de suas ações (vv. 18g.20h), a morte ou a vida do profeta dependerão de ter cumprido seu papel de sentinela, ter dado ou não o alerta sobre a conduta do malvado ou do justo, indicado pelo "e não" - וְ (vv. 18cd.20e).

Nada, porém, se diz quanto aos sentimentos que o profeta poderia experimentar: alegria pelo malvado que se converte ou tristeza por um justo que se deixa corromper e pode ser castigado por seu pecado, por não ter se convertido.

O alerta, "quer te escutem quer não escutem", já permite entrever as possibilidades da missão, pois os destinatários "são uma casa de rebeldes" (Ez 2,7), que nem YHWH, na sua intenção, ou o profeta, por sua missão cumprida, fracassaram (ABREGO, 2011, p. 50-51). ${ }^{11}$

YHWH, que quer a vida e não a morte (Ez 18,23.31; 33,11), deu ao malvado e ao justo, que pecou, a chance de se converter, e quis envolver o seu mediador nessa oportunidade, mostrando que a responsabilidade pessoal implica, igualmente, em responsabilidade social. ${ }^{12}$

\footnotetext{
${ }^{9}$ A $s^{e}$ tûma', posta no final do v. 19 e do v. 21, funciona como sinal delimitador desses dois momentos (KELLEY; MYNATT; CRAWFORD, 1998, p. 115-56).

${ }^{10}$ A sentença que poderia recair sobre Ezequiel é preventiva, a fim de que não seja conivente com a maldade, instalada e praticada em Jerusalém (Ez 24,6-11), comparada à violência de Caim contra Abel. Um crime de sangue que clamou pela justiça divina (BLOCK, 1997, p. 779).

${ }^{11}$ Sobre os destinatários da profecia de Ezequiel em relação a Isaías e Jeremias: "Se identifica a los opositores, particularmente aguerridos: en Isaías son «ciegos y sordos», en Jeremías «atentadores cada vez más violentos», en Ezequiel «hereditariamente rebeldes», a los que se les aplican dos fuertes metáforas, «cardos y escorpiones», obtusos en su interior" (SAVOCA, 1992, p. 58).

12 Parece que por detrás de Ez 18 e 33, além de retomar o tema da prosperidade do ímpio (Jr 12,1), Ezequiel faz uma crítica à tradição de fé coletiva e, Habacuc, de igual modo, atesta que o justo viverá por sua fidelidade (Hab 2,4). Israel é um povo, mas cada um é responsável diante de YHWH, do seu próximo e de si mesmo. "Não existe
} 


\section{Estrutura e gênero literário}

Um olhar, a partir da análise da forma, permite entrever os pontos que determinam a estrutura de Ez 3,16-21. É aberto por um aspecto temporal (v. 16a), seguido de uma fórmula de introdução, origem da Palavra (v. 16b), tendo um destinatário mediador da Palavra, "fillho do homem", e um destinatário último da Palavra, "casa de Israel" (v. 17), dividido em dois grupos: malvado (v. 18-19) e justo (v. 20-21). Quanto ao profeta, punição (v. 18h.20i) ou salvação (v. 19d.21f) dependerão se ele agiu ou não como sentinela, isto é, de acordo com a missão recebida de YHWH, em função da salvação dos seus interlocutores.

Os possíveis casos se tornam a base textual, para os quais existe um alerta que fica na dependência da resposta humana. Esta, por sua vez, terá consequências desfavoráveis ou favoráveis. A casuística das quatro ações fundamenta as sentenças de morte ou de vida, e corresponde ao esquema da retribuição: ao ímpio cabe a condenação: "certamente morrerá" (v. 18b), por sua própria culpa (v. 19c), mas se houver conversão, viverá (v. 18f), e ao justo, que pecou, também cabe a morte, porque não foi alertado para que se convertesse (v. 20d), mas, se for alertado e se converter, receberá absolvição e "certamente viverá" (v. 21d).

Essa percepção denota a compreensão e a formalização, quanto ao gênero literário, de um pronunciamento de tipo jurídico. É um estilo típico legal que confere à função profética de Ezequiel uma forma pastoral particular de se ler e de se interpretar a Torá, em particular a exortação sobre os dois caminhos: "Vê, te expus a vida e o bem, a morte e o mal" (Dt 30,15; S1 1). ${ }^{13}$ Aquele que ouve, assimila e pratica as leis, viverá. Esta é a bênção. Ao contrário, quem não ouve, assimila ou pratica as leis, morrerá. Esta é a maldição (Dt 11,26-28).

Então, Ez 3,16-21 pode ser organizado de uma forma bem simples: Introdução (v. 16); Destinatários (v. 17); duas casuísticas sobre o malvado: morte, por não ter sido alertado pelo profeta (v. 18), e morte por não ter se convertido diante do alerta (v. 19); duas casuísticas sobre o justo: morte, por não ter sido alertado pelo profeta (v. 20), e vida por ter sido alertado a não pecar (v. 21). A responsabilidade pessoal de Ezequiel concorre nas duas casuísticas.

Um esquema simples permite visualizar o conteúdo da fala de YHWH ao profeta Ezequiel (ALONSO SCHÖKEL; SICRE DIAZ, 1991, p. 711):

$\begin{array}{lll}\text { caso do ímpio: } & \text { se não o advertires: } & \begin{array}{l}\text { destino seu/teu } \\ \text { destino seu/teu }\end{array} \\ & \text { se o advertires: } & \text { destino seu/teu } \\ \text { caso do justo: } & \text { se não o advertires: } & \text { destino seu/teu }\end{array}$

Nos dois casos, o sangue do malvado e do justo, que morrem por não terem sido alertados, estará nas mãos do profeta. Nota-se que não há uma recompensa para o profeta por ter cumprido com a sua missão, simplesmente não será responsabilizado pelas mortes e sua vida será preservada. A recompensa restringe-se à atitude obediencial do profeta a YHWH.

\footnotetext{
mais o povo como partner da aliança, até quando Deus instituirá para esse a 'aliança eterna', mas, no período de transição, para cada pessoa de Israel foi aberto uma relação com Deus semelhante a uma aliança: cada um é colocado, como antes tinha sido o povo, diante de uma encruzilhada entre vida e morte. Isto vale com uma particular intensidade na hora que precede a catástrofe, na hora, então, na qual e pela qual Ezequiel, enviado à 'casa de Israel', como 'explorador' e admoestador das pessoas (3,17-21), pronuncia a sua mensagem da responsabilidade pessoal" (BUBER, 1985, p. 184).

${ }^{13}$ Nesse sentido, Ezequiel aparece como um "novo" Moisés a favor do povo (Ex 34,5-9), porta-voz de YHWH que relê a justiça da Torá nos moldes do arrependimento e da conversão, capazes de mudar a sentença e apontar um caminho de esperança (BLOCK, 1997, p. 557).
} 


\section{Breve comentário exegético-teológico}

A fórmula, "veio a mim a Palavra de YHWH", é predominante no livro do profeta Ezequiel. ${ }^{14}$ Três dados são particulares nessa fórmula: 1) $\mathrm{O}$ verbo está no wayyiqtol (sinal macrossintático de uma narrativa); 2) atesta-se a origem da palavra; 3) o destinatário está na primeira pessoa do comum singular.

Em relação aos demais livros proféticos, a regularidade no uso dessa fórmula no livro de Ezequiel permite dizer que se está diante de uma narrativa ininterrupta, a respeito de uma pessoa que recebeu um encargo ligado exclusivamente à Palavra de YHWH (BRETÓN, 1987, p. 41, 43). O profeta é a testemunha do que ouve e a voz qualificada do que deve falar. Assim, em sua composição, a fórmula encerra um fenômeno: A Palavra de YHWH, dirigida ao profeta, é um acontecimento que o envolve e o responsabiliza, em primeiro lugar, perante YHWH e, depois, junto aos seus interlocutores.

Por mais simples que possa parecer, a dimensão do acontecimento é o elemento que permite olhar para o conteúdo do livro profético e declarar uma certeza: a palavra tem origem divina, mas foi destinada ao ser humano, comprometendo igualmente a pessoa do mediador. Isto garante o caráter histórico da palavra de YHWH, pois está anunciada para uma pessoa e foca em realidades concretas. Apoia essa afirmação a referência temporal do v. 16a que abre a narrativa também pelo mesmo verbo no wayyiqtol ("e aconteceu ao final de sete dias"). ${ }^{15}$

Essa referência temporal, embora não se diga em que dia da semana aconteceu, pode ser indicadora de uma semana completa, o que incluiria o shabbat. Desse modo, se conjuga ação com contemplação. O tempo previsto foi do primeiro ao sétimo dia. O que veio antes - a visão do carro de YHWH (teofania), e a visão do livro (fonte da vocação) - necessitou de uma semana de reflexão para que Ezequiel se inteirasse do sentido da teofania e do que os exilados estariam passando (Ez 3,15: "permaneci ali por sete dias").

Sete dias, para além do tempo empregado por Deus, para realizar a criação (Gn 1,1-2,4a), é, do ponto de vista humano, o tempo que se dedica à lamentação por uma realidade constrangedora (Jó 2,13). Esse dado aparece corroborado pelo conteúdo da visão do livro: "lamentações, prantos e ais" (Ez 2,10). A nova irrupção de YHWH, na vida de Ezequiel, conjuga os dois atos, pois diante do caos do exílio, YHWH propõe um ato recriador que, desta vez, dependerá da resposta tanto do povo, malvado ou justo, como da ação do profeta.

Talvez, sobre essa realidade septenária, seja possível entrever a força que reside na fórmula "filho do homem". Ezequiel é um "fillho de Adão", portador da condição que constitui o ser humano fragilizado e, se não fosse a graça divina, ficaria condicionado no seu ser e no seu agir pela força do pecado. ${ }^{16}$ Não obstante isso, foi para o ser humano que YHWH endereçou a sua palavra em função dos demais filhos de Adão, referidos pela locução: “casa de Israel”. Se no Jardim de Éden, a serpente foi uma voz que deturpou a Palavra de YHWH e enganou os progenitores (Gn 3), em Babilônia (se pense nos jardins suspensos), Ezequiel foi constituído uma "sentinela para a casa de Israel", não para perscrutar a fim de corromper ou levar à morte, mas para vigiar e reencaminhar os deportados para a vida.

A ideia de sentinela da casa de Israel não é, por certo, uma novidade profética. Há textos atestando que essa função já havia sido praticada, pela qual se anunciava que um perigo se

\footnotetext{
${ }^{14}$ Quarenta e uma vezes em Ezequiel contra seis em Jr 1,4.11; 2,1; 13,8; 16,1; 18,5; 24,4; e duas em Zc 4,8; 6,9.

${ }^{15}$ Ez 1,1-3 é aberto pelo verbo hāyâ no wayyiqtol (1יְְi) e contém os principais elementos de uma narrativa sobre a qual se estribará a profecia: Tempo ("trigésimo ano, no quinto dia do quarto mês... no quinto dia do mês, isto é, no quinto ano do exílio"), local ("junto ao rio Cobar... na terra dos caldeus, junto ao rio Cobar"), personagens ("me encontrava entre os exilados... rei Joaquim... sacerdote Ezequiel, filho de Buzi" + "visões de Deus", "Palavra de YHWH" e "mão de YHWH"), e ações ("os céus se abriram e tive visões de Deus... veio a Palavra de YHWH... ali pousou sobre ele a mão de YHWH).

${ }^{16}$ Se, por um lado, a locução, "filho do homem", indica que Ezequiel é um ser humano, por outro lado, serve para enfatizar "a finitude do profeta que se defronta com a transcendência de Deus" (MARTENS, 1998, p. 191).
} 
aproximava de um povo rebelde e incapaz de percebê-lo (Os 9,8; Is 21,6-8; Jr 6,17). Com Ezequiel, porém, pode-se advogar a favor de uma novidade, pois a função de sentinela se tornou um ofício jurídico, visto que passou a ter consequências de vida ou de morte não só para os implicados no anúncio, mas também para quem recebeu o encargo de anunciar.

A lógica da comunicação é clara: YHWH dirige a sua palavra ao profeta que, por sua vez, deve, sob pena de vida ou de morte, transmiti-la ao indivíduo: malvado ou justo. Se o profeta não transmite a mensagem recebida de YHWH e o malvado ou justo, que pecou, não forem alertados de que morrerão por sua culpa, o profeta se torna responsável e culpado tanto pela morte do malvado como do justo que pecou. Se o profeta alerta o malvado ou o justo que pecou de que morrerão por sua culpa, mas estes não escutam o alerta, então o profeta não se torna responsável e culpado pela morte quer do malvado quer do justo que pecou. ${ }^{17}$

Em ambos os casos, YHWH quer a conversão do malvado de seu mau caminho e que o justo não cometa uma iniquidade, para que não venha a morrer por causa disso. Dado singular surge nessa relação: o ofício de sentinela se converte em uma "alienação pessoal", critério de justiça, pois se transfere, igualmente para o profeta, a dupla possibilidade de sentença. A ação do profeta, então, não pode ir além da decisiva vontade de YHWH para a casa de Israel. ${ }^{18}$

Sobre o destinatário da Palavra de YHWH, "casa de Israel", merece um particular esclarecimento, porque, também para esse caso, o maior número de atestações dessa locução encontra-se no livro do profeta Ezequiel. ${ }^{19}$

A primeira ocorrência está em Ex 16,31 como sujeito que chamou de "maná" ao dom do alimento que YHWH concedeu aos que marchavam pelo deserto. Nesse livro, a "casa de Israel" indica os filhos de Israel, isto é, os descendentes das doze tribos de Jacó que deixaram a opressão do Egito sob a liderança de Moisés e aos quais YHWH propôs a aliança (Ex 19,3).

O mesmo significado deveria ser atribuído aos outros três textos presentes na Torá (Ex 40,38; Lv 10,6; Nm 20,29), e aos textos que, pela narrativa, seriam anteriores à unificação das tribos (Js 21,45; Rt 4,11; $1 \mathrm{Sm} \mathrm{7,2-3;2Sm} \mathrm{1,12;} \mathrm{6,5.15),} \mathrm{sob} \mathrm{o} \mathrm{reinado} \mathrm{de} \mathrm{Davi} \mathrm{(2Sm} \mathrm{5,1-5;}$ $6,5.15 ; 12,8)$. A distinção ganha conotação política a partir da cisão do reino com Roboão e Jeroboão I (1Rs 12,20-21). Assim, a partir dessa cisão, a locução “casa de Israel” passou a equivaler ao Israel norte ou Reino do norte até a sua destruição pelos assírios em 722/21 a.C.

Então, ao que tudo indica, a locução "casa de Israel", no livro do profeta Ezequiel, não teria uma conotação dinástica, mas equivaleria a "filhos de Israel" ou a "israelitas". Uma exceção encontra-se na referência conjunta: "casa de Israel e de Judá" (Ez 9,9), e no ideal de unificação em Ez 37,16. A favor dessa leitura está o parco uso da locução "casa de Judá" que, nos tempos de Ezequiel, equivalia ainda à Davi e à sua descendência (Ez 4,6; 8,17). Sob tal lógica, Ez 25,3.8.12 evoca o momento em que se deu a primeira deportação do rei Joaquin, sua família, dignitários, a classe sacerdotal, sábios e artífices em 598/97 a.C. (2Rs 24,8-17). Ezequiel, provavelmente, fazia parte desse grupo de deportados, mas não entrou logo em cena. YHWH começou a se manifestar a ele em visões no quinto ano do exilio, isto é, em 593/92 a.C. $(\mathrm{Ez} 1,2){ }^{20}$

\footnotetext{
${ }^{17}$ A prestação de contas pedida a Ezequiel sobre a morte do malvado ou do justo, que não foi advertido do seu erro, encontra eco na posição de 'Elōhîm em relação ao gênero humano, após o dilúvio, como em Gn 9,5-6. Esta sentença, por sua vez, ecoa o pedido de contas de YHWH a Caim em Gn 4,9-16. A diferença recai sobre a não sentença de morte para Caim. O seu "castigo" está no sinal que, além de proteger Caim da morte, não o deixaria esquecer o que fez ao seu irmão. Sobre a questão da violência em Gn 1-11 (WÉNIN, 2019, p. 397-430).

${ }^{18}$ Sem dúvida, um passo ulterior se encontra no Profeta por excelência, Jesus, pois além de ter cumprido a sua missão, chamando o povo à conversão e ao arrependimento, alertando sobre as consequências para quem se fizesse surdo à sua voz, também assumiu, sobre si, a pena de morte que, pelo pecado, a todos se tornou devida.

${ }^{19}$ A título de exemplo: Ez 4,3; 12,6; 24,2128,24; 29,6.16.21; 33,7; 36,22.37; 40,4; 45,8.

${ }^{20}$ Pouco provável que o profeta Ezequiel tenha testemunhado a libertação de Joaquin do cárcere pela ordem de Evil-Merodac entre os anos 562-560 (2Rs 25,27-30), apesar de Ez 1,1 referir-se a uma data próxima desse evento: "No trigésimo ano, no quinto dia do quarto mês". Esta referência etária poderia ser uma alusão à "idade mínima
} 
Por que Ezequiel foi chamado a ser sentinela para a casa de Israel se estava entre os exilados? Seria em função dos exilados ou dos remanescentes de Judá-Jerusalém após a primeira deportação? Ou porque YHWH quis inaugurar uma nova perspectiva dentro do profetismo clássico pautada na responsabilidade individual ${ }^{21}$ Como, ou de que modo, a imagem da sentinela poderia ajudar a dar respostas para essas questões?

Antes de se tornar uma "profissão", a figura da sentinela evocava algo inerente ao ser humano: estar sempre alerta e vigilante para evitar toda e qualquer ocasião capaz de colocar em risco a sua vida pessoal, familiar ou tribal. Pela própria evolução, o ser humano foi aprendendo o valor da percepção atenta da realidade e da cautela a ser tomada diante dela. Ao lado do vigiar o que acontecia à sua volta, o ser humano precisou aprender a decifrar, pela sua razão, os alertas dos sentidos, criando mecanismos de defesa e de autopreservação.

Na Sagrada Escritura, a sentinela é uma figura de prevenção diante de situações que põem em perigo de morte: ataque de feras aos rebanhos ou de inimigos, tentando invadir um campo, um vilarejo ou uma cidade que, na maioria das vezes, era fortificada e com torres de vigia. Não à toa, Jerusalém era uma cidade estratégica, pois estava a quase 800 metros acima do nível do mar Mediterrâneo. Certos locais se tornaram cidades-estado por serem pontos que permitiam o controle de toda a região, Meggido é um bom exemplo. Js 17,11-12 afirma que Manassés teve controle dessa região e edificou uma torre.

$\mathrm{O}$ primeiro relato, segundo a narrativa bíblica, que pode ser associado à sentinela encontra-se em Gn 3,24: YHWH colocou querubins, na entrada do Jardim de Éden, para guardar (vigiar) o caminho da árvore da vida. Algo que chama a atenção. Acaso YHWH não é onisciente, capaz de conhecer as intenções humanas; onipresente, capaz de vigiar, ele mesmo, esse caminho; e onipotente, capaz de impedir tal tentativa? Sim, mas houve uma alocação, visto que o ser humano tinha sido o primeiro a receber a tarefa de guardião (Gn 2,15). Parece que Ez 28,14 evoca essa ação, mas os querubins, à diferença de Gn 3,24, além de vigiar, também deviam executar as ordens de YHWH.

Para uma sentinela, a noite era o momento mais crítico e tenso do seu encargo. Por isso, ansiava pela aurora (Is 21,11-12). Nas planícies ou campos, buscava-se um ponto estratégico, um monte que propiciasse a observação mais ampla do local $(\mathrm{Nm} 23,14)$. Já em uma cidade, a sentinela estava em uma torre de vigia (2Sm 18,24-27; 2Rs 9,17-21). ${ }^{22}$ Em Judá, os locais de vigia das sentinelas também serviram como prisão temporânea $(\mathrm{Jr} 32,2.8 .12 ; 33,1 ; 37,21$; $38,28)$, que foi restaurada nos tempos de Neemias ( $\mathrm{Ne} 3,25 ; 12,39)$. Até no caminho, podia se colocar uma sentinela para espreitar os transeuntes ( $\mathrm{Jr} 48,19)$.

O verbo șāpāh, na sua primeira acepção, significa "vigiar", "guardar atentamente", "observar ao redor", "espreitar". ${ }^{23}$ Assim, o particípio hebraico șōpeh indica a pessoa que vigia, observa ou espreita a realidade com atenção $(1 \mathrm{Sm} 4,13)$. Na dependência do contexto, pode-se admitir shōmer como sinônimo de șōpeh $(\mathrm{Gn} 4,9)$.

do ministério sacerdotal segundo Nm 4,3.23.30.35.39.43.47" (ALONSO SCHÖKEL - SICRE DIAZ, 1991, p. 705). Contudo, há quem questione a hipótese acima, seguindo a cronologia presente no livro (1,2: quinto ano; 8,1 : sexto ano; 20,1: sétimo ano; 24,1: nono ano; 29,1: décimo ano; 26,1; 30,20; 31,1: décimo primeiro ano; 32,1; 32,17; 33,21: décimo segundo ano; 40,1: vigésimo quinto ano; 29,17: vigésimo sétimo), é possível estimar uma data para o fim das atividades de Ezequiel perto de 566 a.C., a partir de 594/93 a.C. (ABREGO, 2011, p. 11.2021.37), ou 571 a.C. se contado a partir de 598/97 a.C., ano da primeira deportação (EICHRODT, 2001, p. 7, 70).

${ }^{21}$ Embora exista um pano de fundo da teologia sacerdotal, com ênfase na responsabilidade coletiva, os exemplos contidos no livro de Ezequiel apontam fortemente para a inovadora compreensão da responsabilidade individual (TUELL, 2009, p. 16).

${ }^{22}$ Noção bem próxima do sentido empregado em Ez 3,17 (TUELL, 2009, p. 15).

${ }^{23}$ Sinônimos de șāpāh: nāțar ("manter guarda"), nāṣar ("guardar", "vigiar"), miṣpeh ("torre de vigia"), șippîyâ ("posto de observação"), šāmar ("vigiar", "ter cuidado", "montar guarda"). A primeira ocorrência de șāpāhh aparece no nome próprio, miṣpâ (Gn 31,49), sinal do tratado entre Labão e Jacó. Por isso, Labão disse: "YHWH espreita entre mim e ti". A fala serve como uma espécie de juramento legal no tocante às filhas e soa muito mais como uma ameaça do que uma bênção de Labão para Jacó (SCHOVILLE, 2011, p. 828-29). 
No Antigo Oriente Próximo, para ser uma sentinela, não bastava possuir boa visão, era preciso que fosse capaz de reconhecer o que estava vendo e fosse rápido para, coerentemente, interpretar e dizer o que foi observado (2Sm 13,34; 18,24-27; 2Rs 9,17). Dar um alarme falso ou falhar no encargo de sentinela poderiam ser ações catastróficas. Em geral, a sentinela, se falhasse, era executada. Ao lado disso, precisava ser ágil o bastante para tirar vantagem da situação observada, em particular para estar à frente de um possível ataque inimigo.

O S1 37,32 afirma que “o ímpio espia o justo para fazê-lo morrer". Já o S1 66,7 afirma que os olhos de Deus vigiam as nações, a fim de que os rebeldes não se exaltem. Algo mais abrangente, encontra-se em Pr 15,13, pois afirma que em todo lugar os olhos de YHWH perscrutam os malvados e os bons. Digno de louvor, porém, é encontrar a mulher virtuosa que não só vigia, mas discerne o comportamento dos servos que trabalham em sua casa $(\operatorname{Pr} 31,27)$.

A derrota e a queda de Babilônia foram anunciadas por YHWH a Isaías, colocado de prontidão como uma sentinela diurna e noturna (Is 21,6). Melhor que a derrota de um inimigo é o grito da sentinela anunciando o retorno de YHWH para Sião (Is 52,8). Triste, porém, é assemelhar as lideranças do povo a sentinelas cegos, pois não veem; a cães mudos, pois não falam. Só querem se deleitar em seu próprio caminho (Is 56,10). É igualmente lamentável quando o povo não dava ouvidos às sentinelas, provavelmente os profetas $(\operatorname{Jr} 6,17)$. Pior foi esperar ajuda de quem não se importou com o pedido de socorro ( $\operatorname{Lm~4,17).~}$

Tanto a Samaria, como Nínive, a sua devastadora, estiveram sob os olhares de profetas sentinelas que, por um lado, constataram o desaparecimento do fiel e do justo da face da terra, vendo o violento florescer (Mq 7,4.7); por outro lado, contemplaram a destruição do inimigo impiedoso (Na 2,2). Apesar das experiências nefastas, o profeta, fiel a YHWH e à sua missão, não deixa o seu posto de sentinela, certo de que YHWH responderá à sua queixa (Hab 2,1).

Com base nesses usos, pode-se dizer que o profeta Ezequiel, feito sentinela, precisa ser capaz de vigiar tanto os movimentos do mundo exterior como do mundo interior. Na verdade, o que se passa fora do ser humano tem as suas raízes no seu íntimo, pois assim como "a boca fala do que o coração está cheio", as ações são como frutos, capazes de revelar a natureza da árvore (Mt 12,33-34).

Com relação ao mundo exterior, cabe à sentinela o discernimento dos movimentos e dos sinais que lhe são visíveis desde o seu ponto de observação. Com relação ao mundo interior, adentra-se em uma área na qual, do ponto de vista bíblico, apenas Deus é, de fato, o único que conhece tudo o que se passa no íntimo do ser humano. Contudo, visto que o agir segue o ser, o conhecimento determina o comportamento, mostrando o que está no íntimo do ser humano.

Nesse contexto, a morte, vista como castigo, seria uma consequência da destruição de Judá-Jerusalém causadas pelas mãos dos babilônios. Então, a morte anunciada não deveria ser entendida como uma condenação eterna, pois, na época de Ezequiel, não havia começado a reflexão sobre a ressurreição. Assim, escapar com vida equivaleria à salvação e foi entendida como uma recompensa para o justo, visto que a prata e o ouro não poderiam salvar quando se ocorresse a manifestação do justo juízo divino no yôm YHWH (Sf 1,18).

\section{Considerações finais}

YHWH, ao se dirigir a Ezequiel o fez de maneira verbal. Contudo, devido à missão que foi atribuída ao profeta, pode-se dizer que a linguagem usada é mista: a) Não verbal, pela posição de sentinela que assume frente às pessoas; b) Verbal, pelo alerta que o profeta deve fazer, caso não queira se tornar réu por omissão.

A fala de YHWH ao profeta não deixa, por certo, algum tipo de ambiguidade. É clara, concisa, objetiva e vai direto ao ponto da questão. Os enunciados usados estão, devidamente, ajustados aos seus intencionais propósitos divinos: quer a salvação e não a condenação do ser 
humano, ainda que esta seja apresentada como uma variante possível. Pode-se dizer que a conclusão é óbvia: YHWH revela as suas intenções sem duplos sentidos.

Nos tempos atuais e virtuais, vive-se debaixo da grande sofisticação dos sistemas de vigilância. Os inúmeros satélites, empregados com essa finalidade, provam isso. Contudo, a vocação e a missão de Ezequiel continuam a evocar a necessidade da sentinela entre os seres humanos, a fim de alertar, de forma oportuna e inoportuna, a vontade salvífica de Deus. Sem o compromisso com o bem-estar coletivo, nenhum indivíduo conseguirá ser plenamente feliz.

Como Deus vigia o seu povo com atenção, como a pupila dos seus olhos (Dt 32,10), que cada crente, além de ser capaz de vigiar sobre a própria vida, a fim de se manter fiel, se saiba responsável pelo bem-estar físico e espiritual do seu próximo. Esta postura é condizente com a nova e eterna aliança (Jr 31,31-34). Assim, o resultado, na vida de quem busca viver e ensinar o caminho da retidão, não será um moralismo, mas a coerência de vida por palavras e ações, ou seja, o testemunho da caridade vivida na verdade e desta praticada com caridade.

Portanto, não basta detectar os perigos, é preciso saber lançar o devido alerta, a fím de que o ser humano de qualquer época e lugar não se torne uma presa fácil de um sistema políticoreligioso corrupto e corruptor. Que os atalaias hodiernos, homens e mulheres crentes ao serviço de Deus e de seu reinado, pela incondicional obediência da fé, saibam se posicionar diante da realidade, a exemplo de Jesus Cristo, com apurada percepção e perspicaz reflexão.

\section{Referências bibliográficas}

ABREGO, José Maria. Ezequiel. (Comentarios a la nueva Biblia de Jerusalén). Bilbao: Desclée De Brouwer, 2011.

ALONSO SCHÖKEL, Luis; SICRE DIAZ, José Luis. Profetas II: Ezequiel, Profetas menores, Daniel, Baruc, Carta de Jeremias. São Paulo: Paulinas, 1991.

BLOCK, Daniel I. The Book of Ezekiel - Chapters 1-24. Grand Rapids, MI: Eerdmans, 1997. BRETÓN, Santiago. Vocación y misión: formulario profético. Roma: Editrice PIB, 1987.

BUBER, Martin. La fede dei profeti. Genova; Milano: Marietti, 1985.

CAHINGA, Jerónimo. O fim da iniquidade, esperança de uma nova era: ma leitura apocalíptica de Ez 7. Roma: s/ed, 2003.

DORSEY, David A. The literary structure of the Old Testament: a commentary on GenesisMalachi. Grand Rapids, MI: Baker Books, 1999.

EICHRODT, Walther. Ezechiele (capp. 1-24). Brescia: Paideia, 2001.

KELLEY, Page H.; MYNATT, Daniel S.; CRAWFORD, Timothy G. The Massorah of Biblia Hebraica Stuttgartensia. Introduction and Annotated Glossary. Grand Rapids, MI: Eerdmans, 1998.

MARTENS, Elmer A. "“ִּ" (\# 254). In: HARRIS, R. Laird; ARCHER Jr. Gleason L.; WALTKE, Bruce K. Dicionário Internacional de Teologia do Antigo Testamento. São Paulo: Vida Nova, 1998, p. 190-193.

OLLEY, John W. Ezekiel. A Commentary based on Iezekiēl in Codex Vaticanus. Leiden: Brill, 2009.

SAVOCA, Gaetano. Guia espiritual del Antiguo Testamento. El libro de Ezequiel. Barcelona; Madrid: Editorial Herder; Ciudad Nueva, 1992.

SCHOVILLE, Keith N. "“ָָָָָ" (\# 7595). In: GEMEREN, Willem A. van. Novo Dicionário Internacional de Teologia e Exegese do Antigo Testamento. Vol. 3. São Paulo: Cultura Cristã, 2011, p. 828-829.

TUELL, Steven. Ezekiel. Grand Rapids, MI: Baker Books, 2009.

WÉNIN, André. L'Histoire des origines (Gn 1,1-11,26). Stratégie narrative et parcours théologique. Revista Catalana de Teologia, v. 44, n. 2, p, 397-430, jul./des. 2019.

WOLFF, Hans Walter. Bíblia Antigo Testamento. Introdução aos escritos e aos métodos de estudo. 3. ed. São Paulo: Teológica; Paulus, 2003. 